\title{
WebQuest en clases de Ciencias: Propuesta de Formación Docente para pensar y actuar en los primeros años escolares
}

\author{
Ana Elisabeth Dias Pereira Cavalcante ${ }^{1}$ \\ bethdcp@hotmail.com \\ https://orcid.org/0000-0003-4154-8331 \\ France Fraiha-Martins ${ }^{1}$ \\ francefraiha@ufpa.br \\ https://orcid.org/0000-0001-7933-6014 \\ ${ }^{1}$ Universidade Federal do Pará (UFPA, Brasil)
}

Recibido: 31/05/2020 Aceptado: 09/08/2020

\begin{abstract}
Resumen
Esta investigación es un curso de educación continua para maestros que enseñan ciencias en los primeros años escolares. La propuesta se basa en prácticas de investigación que utilizan WebQuest, especialmente dentro del alcance del contenido del ciclo hidrológico. Nuestro objetivo es investigar los términos en los que esta propuesta contribuye a nuevas formas de pensar y actuar en la educación científica para los primeros años escolares. Guiado por el trípode: Práctica de investigación, Experimento de investigación y Tecnología digital, el diseño de capacitación busca superar las prácticas de enseñanza de ciencias basadas únicamente en libros de texto, con actividades pasivas y reproductivas de los estudiantes. Para ello, realizamos una investigación cualitativa, en la modalidad narrativa, que muestra informes de tres profesores participantes, grabados a través de: entrevista semiestructurada y grabación de audio de las reuniones formativas. Utilizamos el análisis de texto discursivo como metodología analítica. Los resultados revelan, entre otros aspectos, que los maestros comienzan a considerar que el uso de WebQuest en clase crea posibilidades para expandir e integrar la dinámica de la enseñanza y el aprendizaje de las ciencias, ya que proporciona interdisciplinariedad y articulación entre las diversas tareas disponibles en WebQuest. Además, las propuestas de capacitación que favorecen el uso de tecnologías digitales gradualmente permiten al maestro pasar del uso limitado al uso potencial de las tecnologías digitales en situaciones de enseñanza.
\end{abstract}

Palabras clave: Formación de profesores; Tecnologías digitales; Prácticas de investigacion; WebQuest; Enseñanza de las ciencias; Escuela primaria.

\section{WebQuest em aulas de Ciências: Proposta de Formação Docente para pensar e agir nos anos escolares iniciais}

\section{Resumo}

Esta pesquisa trata-se de curso de formação continuada para professores que ensinam ciências nos anos escolares iniciais. A proposta pauta-se em práticas investigativas utilizando WebQuest, especialmente, no âmbito do conteúdo ciclo hidrológico. Objetivamos investigar em que termos tal proposta contribui para novas formas de pensar e agir no ensino de ciências para os primeiros anos escolares. Balizado pelo tripé: Prática Investigativa, Experimento Investigativo e Tecnologia Digital, o design de formação busca ultrapassar práticas de ensino de ciências pautadas unicamente nos livros didáticos, com atividades discentes passivas e reprodutivistas. Para tanto, assumimos a pesquisa 
qualitativa, na modalidade narrativa, evidenciando relatos de três professores participantes, registrados por meio de: entrevista semiestruturada e audiogravação dos encontros formativos. Utilizamos a Análise Textual Discursiva (ATD) como metodologia analítica. Os resultados revelam, dentre outros aspectos, que os docentes passam a considerar que o uso de WebQuest em aula cria possibilidades de ampliar e integrar a dinâmica de ensinar e aprender ciências, pois proporciona interdisciplinaridade e articulação entre tarefas variadas disponíveis na WebQuest. Ademais, propostas formativas que privilegiam o uso de tecnologias digitais permitem, paulatinamente, que o docente avance da prática de uso limitada para a prática de uso potencial das tecnologias digitais em situações de ensino.

Palavras-chave: Formação docente; Tecnologias digitais; Práticas investigativas; WebQuest; Educação em ciências; Anos escolares iniciais.

\title{
WebQuest in Science classes: Teacher Education Proposal to think and act in the elementary school
}

\begin{abstract}
This research is a continuing education course for teachers who teach science in the elementary school. The proposal is based on investigative practices using WebQuest, especially within the scope of the hydrological cycle content. We aim to investigate how this proposal contributes to new ways of thinking and acting in science education for the first school years. Guided by the tripod: Investigative Practice, Investigative Experiment and Digital Technology, training design seeks to overcome science teaching practices based solely on textbooks, with passive and reproductive student activities. For this, we took on qualitative research, in the narrative modality, evidencing reports from three participating teachers, registered through: semi-structured interview and audio recording of the formative meetings. We use Discursive Text Analysis as an analytical methodology. The results reveal, among other aspects, that teachers start to consider that the use of WebQuest in class creates possibilities to expand and integrate the dynamics of teaching and learning science, as it provides interdisciplinarity and articulation between the varied tasks available on WebQuest. In addition, training proposals that favor the use of digital technologies gradually allow the teacher to move from limited use to the practice of potential use of digital technologies in teaching situations.
\end{abstract}

Key words: Teacher education; Digital technologies; Investigative practices; WebQuest; Science education; Elementary school.

\section{Considerações iniciais}

Esta pesquisa trata-se de um curso de formação continuada para professores que ensinam ciências nos anos iniciais do ensino fundamental, com o propósito de subsidiar estudos e reflexões acerca das possibilidades metodológicas, especialmente, para ensinar o conteúdo ciclo hidrológico. A proposta formativa pauta-se em práticas investigativas no ensino de ciências, fazendo uso da tecnologia digital WebQuest ${ }^{1}$ (WQ), que teve como

\footnotetext{
${ }^{1}$ Metodologia de investigação orientada utilizando a internet como um dos principais recursos pedagógicos.
} 
objetivo investigar em que termos tal proposta contribui para novas formas de pensar e agir no ensino de ciências para os primeiros anos escolares.

O processo investigativo e formativo desenvolvido ocorreu com professores que ensinam ciências no $4^{\circ}$ e $5^{\circ}$ ano do ensino fundamental em uma escola pública. A formação continuada de professores se deu por meio de um design de formação, pautado no tripé: prática investigativa, experimento investigativo e tecnologia digital. Tal modelo de formação docente busca ultrapassar as práticas de ensino de ciências pautadas unicamente nos livros didáticos, com atividades discentes passivas e reprodutivistas (Imbernón, 2006). Portanto, priorizamos nessa investigação, aspectos relacionados ao ensino de ciências que privilegiam a aprendizagem do conteúdo escolar para a vida, bem como intencionamos discutir possibilidades formativas para obtenção de atitudes docentes necessárias ao contexto social vigente.

Nesse caminho, Imbernón (2006) evidencia uma vasta e minuciosa abordagem sobre o modelo de formação continuada desejável para o século XXI, enfatizando que esse processo deve partir de dentro da escola, levando em consideração as necessidades e dificuldades dos professores que atuam nesse espaço. É preciso escutar o que os professores dizem sobre suas práticas e a partir dessa escuta desenvolver processo de formação, diz o autor. Imbernón (2006, p.15) destaca sua opção por uma racionalidade prática centrada no contexto, que deve atentar para a criação de espaços de participação, reflexão e formação, pois é urgente: "formar o professor na mudança e para a mudança por meio do desenvolvimento de capacidades reflexivas em grupo, e abrir caminho para uma verdadeira autonomia profissional compartilhada”.

A proposta de formação continuada investigada, surge do conflito entre os movimentos formativos para o uso de novas perspectivas metodológicas e as mudanças efetivas observadas na prática docente no contexto escolar, o que nos leva a questionar sobre a formação de professores e suas experiências metodológicas. Isto porque, pesquisas relativas ao ensino de ciências nos anos escolares iniciais, vêm evidenciando que, em muitos casos, as práticas pedagógicas limitam-se à mera transmissão de conteúdo, além de centralizá-las nas disciplinas de língua portuguesa e matemática, deixando para segundo plano o ensino de conteúdos científicos e suas articulações com a realidade do estudante (Moreira, 2019; Sales, 2019; Castro, 2018; Soares, 2017). 
A respeito dessa articulação com o contexto social, Lorenzetti e Delizoicov (2001), bem como Cachapuz et. al. (2011) sinalizam que mesmo havendo avanços inovadores e significativos de propostas para o ensino de ciências, algumas práticas docentes indicam certo distanciamento do tratamento integrado dos conteúdos científicos escolares às ações cotidianas dos estudantes. Consideramos com os autores, que precisamos, na docência em ciências, permitir a produção de sentidos articulando tais conteúdos à própria vida discente. Para tanto, o professor necessita pensar, criar e mediar processos de ensino que estejam embasados em aspectos que propiciem o engajamento do educando nas atividades de aprendizagens, a fim de desenvolver a criticidade, autonomia e, fundamentalmente, a autoria do aprendiz. Isso vai requerer do professor processos tais como: planejar, discutir, refletir, construir e reconstruir ações que alcancem a motivação para a aprendizagem discente.

Passamos a compreender com Raboni (2002) e Shulman (1986), que as dificuldades apresentadas por professores dos anos escolares iniciais estão atreladas aos seus processos de formação inicial e continuada. Para Raboni (2002), a insegurança do professor em relação ao conhecimento do conteúdo específico de ciências é um dos grandes obstáculos para se ensinar ciências nos anos iniciais do ensino fundamental. Tais dificuldades são geradas, segundo o autor, pelas lacunas na formação recebida sobre conteúdos que deve ensinar. Shulman (1986), corrobora com essa proposição ao destacar que não se pode ensinar o que não se sabe. Para Shulman (1986), ensinar é antes de tudo entender. Entender o conhecimento específico a ser ensinado. Porém, para além da disciplina por si mesma, é necessário o conhecimento para ensiná-la, o que denomina de conhecimento pedagógico do conteúdo.

Nesse sentido, consideramos pertinente ao elaborar e desenvolver a prática formadora em questão, que há uma dupla demanda formativa: estudar/discutir o conteúdo específico a ser ensinado e vivenciar metodologia diferenciada para o ensino desse conteúdo, em especial, o ciclo hidrológico previsto na BNCC - Base Nacional Comum Curricular (Brasil, 2017). Por essa razão, compreendemos que o professor precisa experienciar (Josso, 2004) momentos de formação docente para discutir sobre suas práticas e viver situações de ensino que façam uso de ambientes virtuais no ensino de ciências, dentre outras tecnologias digitais. Sabemos que muitos são os desafios, mas, na condição de docência, precisamos acompanhar os processos de transformação social, tendo em vista que a maioria dos alunos já faz uso desses recursos. O professor tem um papel fundamental 
nesse processo, que é o de mediar a aprendizagem, permitindo a autonomia e a autoria discente (Fraiha-Martins, 2014; Prado, 2006.).

Vivemos hoje influenciados pela ciência e pela tecnologia, portanto, não podemos ignorar tais transformações. Logo, há necessidade de formação com uso de tecnologias digitais, que propicie a tomada de consciência e permita o aprendiz a tornar-se capaz de acessar, selecionar, armazenar, disponibilizar e alterar informações, de modo crítico, a fim de intervir em sua realidade e de fazer as melhores escolhas para a solução de problemas e, ainda, tornar-se autônomo na vida e na profissão. Sendo assim, esta pesquisa é norteada pela seguinte questão principal: Em que termos um curso de formação continuada com práticas investigativas sobre ciclo hidrológico, utilizando WebQuest, pode contribuir para novas formas de pensar e agir no ensino de ciências?

Promover diálogos e discussões sobre o ensino de ciências em processos formativos de professores dos anos iniciais do ensino fundamental é desejável e urgente, uma vez que, propiciar a alfabetização científica desde a infância no educando poderá contribuir para o desenvolvimento do pensamento crítico e cidadão sobre o mundo que o cerca (Chassot, 2006). Consideramos que o professor precisa criar novas habilidades e competências para promover práticas de ensino diferenciadas sob a exigência do contexto social atual. Mas, igualmente, entendemos ser necessário que o professor tenha oportunidade de experienciar processos formativos visando refletir sobre a própria prática docente, bem como experimentar/planejar outras formas de ensinar, preferencialmente, problematizando o conteúdo escolar.

\section{Caminho investigativo}

Fazemos opção por um caminho investigativo qualitativo, na modalidade narrativa. Para Minayo (2008, p. 57) "as abordagens qualitativas se conformam melhor as investigações de grupos e segmentos delimitados e focalizados, de histórias sociais sob a ótica dos atores, de relações e para análises de discursos e de documentos”, tendo como foco as interpretações recíprocas pelos investigadores e sujeitos da ação.

Nesse sentido, nos propomos a investigar um fenômeno educativo de dentro da situação, conforme Deslauriers e Kérisit (2008), que destacam a abordagem qualitativa por considerar que o pesquisador poderá ter o próprio ambiente de atuação para construção do material empírico. Assumimos também a pesquisa narrativa pelo fato de que ela vem sendo 
bastante utilizada em pesquisas educacionais para investigar a experiência humana, apresentando-se pertinente aos processos de investigação que privilegiam a compreensão/interpretação dos relatos dos professores envolvidos na situação investigada.

Segundo Cunha (1997, p. 2), "trabalhar com narrativas na pesquisa e no ensino é partir para desconstrução e construção das próprias experiências tanto do professor como dos sujeitos da pesquisa e do ensino". A abordagem narrativa se constitui como estratégia adequada e fértil para ampliar a compreensão do mundo escolar.

Compactuamos com Clandinin e Connelly (2011, p. 73), quando destacam que a pesquisa narrativa tem a capacidade de transmitir significados no sentido de seu processo de produção, pois "requer uma reconstrução da experiência de uma pessoa [ou de pessoas] em relação aos outros e ao ambiente social ”. Nos dizeres de Clandinin e Connelly (2011, p. 108), as narrativas permitem a construção de novos sentidos e significados à história, visto que "há um processo reflexivo entre o viver, contar, reviver e recontar de uma história de vida”.

Narrar e refletir, considerando a trajetória de processos formativos, pressupõem o uso da memória sobre situações que foram significativas. Além de contribuir com a formação dos envolvidos na "história", a narrativa compartilha experiência com outros sujeitos, em particular com aqueles cujas práticas abordam questões que se relacionam. Pautadas em Clandinin e Connelly (2011), consideramos que as narrativas são processos educativos, pois quem conta, revive a sua história e a ressignifica, saindo do passado para o presente e projetando-se para o futuro, atribuindo-lhe novos sentidos e significados. Por isso mesmo, as narrativas podem se constituir em processos formativos/educativos de grande potência.

No dizer de Cunha (1997, p. 35), a narrativa:

não se trata apenas de um conhecimento implícito na atividade prática. Trata-se, sim, de um diálogo entre a prática vivida e as construções teóricas formuladas nesta e sobre estas vivências. O discurso construído sobre esse diálogo é que torna possível transformá-lo numa situação profundamente pedagógica. A linguagem, aí, é uma poderosa aliada da formação.

Na perspectiva de Cunha (1997) e de Cladinin e Connelly (2011), é que entendemos ser possível construir interpretações das narrativas advindas de professores que ensinam ciências nos anos iniciais do ensino fundamental, no intuito de transformar 
narrativas individuais, no âmbito da formação e da docência, em assertivas propositivas e favoráveis à reflexão e a novas perspectivas de ensino de ciências.

Em termos de contexto, a pesquisa teve como lócus uma Escola Estadual de Ensino Fundamental, situada no município de Ananideua/Pa, em que uma das autoras foi estagiária durante sua formação inicial e professora colaboradora até os dias atuais, mantendo-se formadora-pesquisadora no âmbito dos anos iniciais do ensino fundamental. O processo investigativo e formativo desenvolvido ocorreu com professores que ensinam ciências no $4^{\circ}$ e $5^{\circ}$ ano do Ensino Fundamental. Considerando ser este um recorte de pesquisa mais ampla, optamos por dar evidência às narrativas de três professores participantes desta investigação. Preservando suas identidades, atribuímos os seguintes nomes fictícios: Marcia, Sílvia e Luciano.

Para a obtenção e produção de textos de campo, no contexto da pesquisa mais ampla, utilizamos os seguintes instrumentos de investigação: i) registros em áudio e vídeo dos encontros formativos; ii) produção de materiais e sínteses individuais e coletivas realizadas durante os encontros formativos; iii) questionário; iv) entrevista semiestruturada; v) e registros em diário de campo. O questionário utilizado inicialmente objetivou conhecer e descrever de forma breve os participantes da pesquisa, pontuando aspectos de ordem pessoal, profissional, conhecimento básico sobre a temática de formação: ciclo hidrológico e tecnologias digitais. Os demais instrumentos, por meio das análises, permitiram imersão nas experiências vividas pelos docentes e respectivos conhecimentos adquiridos, contribuindo para melhor sistematização e produção dos resultados da pesquisa.

Diante disso, para realização da análise e tratamento do material empírico, lançamos mão da Análise Textual Discursiva (ATD) que "pode ser compreendida como um processo auto organizado de construção de compreensão, em que novos entendimentos emergem a partir de uma sequência recursiva analítica" (Moraes e Galiazzi, 2007, p. 12). A escolha por analisar as produções textuais e narrativas orais desses professores à luz dessa metodologia analítica deu-se, principalmente, por partir de um olhar cuidadoso e criterioso em um processo de unitarização, na busca por focos de significados e construção analítica, até alcançar categorias emergentes, sejam elas advindas de recorrências ou singularidades, com vistas à compreensão do fenômeno educativo investigado. 
Ao assumirmos a ATD, buscamos organizar conjuntos de ideias com a clareza de que, ao construir uma teia de significação por meio da pesquisa, ela será mais uma interpretação diante do fenômeno estudado, capaz de produzir nova significação a quem ela atingir. Como se referem Moraes e Galiazzi (2007, p. 21), “essa diversidade de sentidos que podem ser construídos a partir de um conjunto de textos está estreitamente ligada às teorias que os leitores empregam em suas interpretações textuais”. Por mais sentidos e significados que se possa evidenciar, sempre haverá outros. Optamos por priorizar neste artigo discussões que situam o modelo de formação continuada realizado e suas repercussões na visão dos docentes envolvidos.

\section{O design de formação continuada para o ensino de ciências}

A intenção de estudar o ciclo hidrológico por meio da temática Escassez Hídrica no contexto de formação continuada, ocorreu pela ênfase dada, pelos documentos oficiais advindos do MEC, às temáticas relativas ao contexto social. À exemplo, citamos a Base Nacional Comum Curricular (Brasil, 2017), os Elementos Conceituais e Metodológicos para Definição dos Direitos de Aprendizagem (Brasil, 2012), além dos Parâmetros Curriculares Nacionais PCNs/Ciências Naturais (Brasil, 1997). Tais documentos destacam que os conteúdos de ciências devem ser explorados a partir de um contexto, propiciando a integração de outros conhecimentos. Também ressaltam que o estudo de um conteúdo curricular de ciências não deve estar atrelado somente à aprendizagem de conteúdos conceituais, mas deve propiciar aprendizagens de conteúdos procedimentais e atitudinais.

O documento dos Direitos de Aprendizagem para os primeiros anos escolares, por exemplo, destaca que as atividades por meio de investigação em aula permitem aos estudantes "oportunidades de levantar hipóteses, organizar informações, propor explicações e produzir relatos acerca do observado" (Brasil, 2012, p.101). Por sua vez, os PCNs (Brasil, 1998) sugerem que os conteúdos conceituais, procedimentais e atitudinais estejam vinculados aos quatro pilares da educação, propostos por Delors (1998): aprender a conhecer; aprender a fazer; aprender a viver; e aprender a ser.

Na unidade temática Matéria e Energia, a BNCC direciona que os estudos da disciplina devem relacionar "o estudo de materiais e suas transformações, fontes e tipos de energia utilizados na vida em geral, na perspectiva de construir conhecimento sobre a natureza da matéria e os diferentes usos da energia" (Brasil, 2017, p. 323). Do mesmo modo, a BNCC propõe que "os alunos possam reconhecer a importância, por exemplo, da 
água, em seus diferentes estados, para a agricultura, o clima, a conservação do solo, a geração de energia elétrica, a qualidade do ar atmosférico e o equilíbrio dos ecossistemas" (Brasil, 2017, p. 323)

Inspiradas nas proposições acima, decidimos, além de priorizar o estudo sobre o ciclo hidrológico em formação continuada, problematizar as ausências formativas já mencionadas, fazendo uso da perspectiva metodológica da Simetria Invertida ${ }^{2}$, por compreender que ela pode contribuir para que o docente assuma essa tendência de prática investigativa no cotidiano da sua profissão (Longhini, 2008). Isto porque, o professor em formação ao vivenciar uma experiência de ensino pautada em escolhas teóricometodológicas desejáveis para o século XXI, espera-se que ele possa refletir sobre suas práticas e fazer uso dessa possibilidade (ou inspirar-se nela) para ensinar ciências em suas aulas.

Em conformidade com a perspectiva assumida no design de formação, elegemos a WebQuest (tecnologia digital) como ferramenta metodológica de ensino para compor o tripé do design formativo. Compreendemos que o uso de tecnologias digitais, em especial a WQ, pode criar possibilidades e potencializar a díade ensino e pesquisa por ser uma ferramenta objetiva e simples. Ela pode ser desenvolvida na escola, proporcionando o uso da internet para propiciar pesquisa orientada, fazendo uso de recurso parcial ou total disponível na WebWordWide (Dodge, 1995).

Nesse sentido, passamos a considerar relevante o professor discutir situações de ensino que façam uso desses ambientes virtuais. Sabemos que muitos são os desafios, mas como educadores dos anos iniciais do ensino fundamental, precisamos acompanhar os processos de transformação social, tendo em vista que a maioria dos alunos já faz uso desses recursos. Para obter processos exitosos de aprendizagem com uso de tecnologias digitais em sala de aula, é necessário conduzir o aluno em um ambiente de discussão, ou seja, é preciso pensar em um ensino que crie situações nas quais o aluno possa se manifestar, proporcionando aprendizagem na perspectiva de construção e não de modo mecânico. A tecnologia nos permite ampliar o conceito de aula, espaço e tempo de comunicação. Vale lembrar que ensinar não depende unicamente da tecnologia em si, ela é uma ferramenta facilitadora desse processo (Coll, Mauri e Onrubia, 2010).

\footnotetext{
${ }^{2} \mathrm{O}$ professor deve aprende do lugar onde ele irá atuar, porém em uma situação invertida (na situação de aluno). Tem que haver coerência entre a formação do professor e o que dele se espera em termos de docência.
} 
Portanto, a WebQuest não é usada somente para obtenção de informações, mas tornase um meio para uma investigação orientada na Web, com fins autorais. É composta por uma estrutura onde o sujeito possa explorar, pesquisar, registrar, sistematizar e comunicar. O planejamento de uma WebQuest é feito por um professor que pensa em tarefas que leva o aluno ao desenvolvimento de atitudes de pesquisador. Isto é, tarefas que propiciam a realização de questionamentos, construção de argumentos e comunicação de resultados da pesquisa realizada.

Para construir e criar uma WebQuest de qualidade é preciso levar em consideração as seguintes sugestões: pensar em um conteúdo socialmente significativo, curricular ou extracurricular. Em nossa proposta escolhemos juntamente com os professores participantes o tema Escassez Hídrica. Assim, passamos a pensar em um conteúdo escolar a ser trabalhado de maneira mais atrativa, partindo de um tema, que pode ser compreendido como motivador para o aluno, no intuito de fazer com que ele se envolva em um processo de investigação, buscando respostas às próprias indagações e sistematizando o que está aprendendo (Fraiha-Martins, 2014).

As atividades que constituem a WebQuest devem integrar o uso da internet em aula, permitindo o trabalho cooperativo entre os estudantes. "É o professor que planeja as atividades investigativas capazes de integrar variadas ações de interatividade entre eles e deles com as tecnologias digitais" (Abar e Barbosa, 2008, p. 11). Assim, o desafiador é pensar em um espaço de aprendizagem em que a WebQuest construída pelo professor seja incluída nesse ambiente. Reiteramos que a WebQuest não é só para obter fonte de informação, mas ela se torna um meio para o processo de pesquisa, por isso, ela se inicia com questões problematizadoras que levem à investigação. Compreendemos com Galiazzi (2003, p. 294), que “os estudantes aprendem melhor quando estão manipulando, explorando, observando e discutindo, ou seja, quando estão verdadeiramente envolvidos no processo". Portanto, diante dos argumentos que destacamos sobre o uso da WebQuest, compreendemos que a mesma é coerente com as proposições assumidas nesta pesquisa e se configura como um ambiente investigativo virtual e viável para (re) significação do ensino sobre ciclo hidrológico.

Sendo assim, passamos para a descrição geral do design de formação continuada desenvolvido ${ }^{3}$. Destacamos que ao mesmo tempo em que os professores estudaram e

\footnotetext{
${ }^{3}$ A WebQuest elaborada e utilizada na formação continuada em questão tornou-se produto educacional resultante da pesquisa e está disponível em http://educapes.capes.gov.br/handle/capes/564965. Ressaltamos
} 
desenvolveram práticas investigativas com o tema Ciclo Hidrológico, eles são levados a pensar o uso desse ambiente investigativo virtual no ensino que realizam ou realizarão.

A construção das tarefas na WQ foi de caráter investigativo, de modo a conduzir à busca, seleção e sistematização de informações, indo ao encontro da construção dos conhecimentos específicos escolares e ao uso social dos vários conhecimentos envolvidos no estudo. Sendo assim, a formação continuada realizada com os professores foi sistematizada em duas grandes fases ocorridas em 6 (seis) encontros presenciais, sendo que cada um tinha propósitos diversificados, almejando os objetivos da ação formadora.

A seguir, apresentamos em formato sintético o desenvolvimento do design de formação continuada investigado:

Quadro 1: Proposta Formativa sobre Ciclo Hidrológico

\begin{tabular}{|c|c|c|c|}
\hline $\begin{array}{c}\text { Etapas da } \\
\text { proposta }\end{array}$ & $\begin{array}{c}\text { Encontros } \\
\text { presenciais }\end{array}$ & Objetivos & Metodologia \\
\hline & $\begin{array}{l}1^{\circ} \text { encontro } \\
\text { (05 horas) }\end{array}$ & $\begin{array}{l}\text { - Conhecer as ideias iniciais } \\
\text { dos sujeitos em relação a suas } \\
\text { práticas de ensino e } \\
\text { importância da formação } \\
\text { continuada }\end{array}$ & $\begin{array}{l}\text { Processo de sondagem de seus } \\
\text { conhecimentos prévios por } \\
\text { meio de diálogos. }\end{array}$ \\
\hline $\begin{array}{l}\text { Conhecendo os } \\
\text { professores } \\
\text { participantes }\end{array}$ & $\begin{array}{l}2^{\circ} \text { encontro } \\
\text { (05 horas) }\end{array}$ & $\begin{array}{l}\text { - Problematizar o conceito de } \\
\text { reflexão docente, discutindo } \\
\text { sobre a importância do } \\
\text { professor refletir sobre sua } \\
\text { própria prática, sensibilizando } \\
\text { os professores para adesão à } \\
\text { participação da pesquisa. } \\
\text { - Reunir informações } \\
\text { primordiais para a construção } \\
\text { do design de formação } \\
\text { continuada. }\end{array}$ & $\begin{array}{l}\text { Mobilização de ideias para a } \\
\text { reflexão docente: } \\
\text { Tema: "O professor que reflete } \\
\text { sobre sua própria prática". } \\
\text { Questões deflagradoras: } \\
\text { - O que é reflexão? Será que } \\
\text { refletir é suficiente para } \\
\text { obtenção de conhecimento, } \\
\text { autonomia e conscientização? } \\
\text { Por que o processo de reflexão } \\
\text { docente é tão desejável e } \\
\text { essencial para o contexto que } \\
\text { vivenciamos atualmente? }\end{array}$ \\
\hline \multicolumn{4}{|c|}{$\begin{array}{l}\text { Tarefas: } \\
\text { 1. Responder por que é importante ser um professor reflexivo? } \\
\text { 2. Construção de um texto orientado pelos seguintes questionamentos } \\
\text { - Quem sou eu como professor? Como me vejo como professor? } \\
\text { - Por que ensino do jeito que ensino? } \\
\text { - Existe alguma prática que desenvolvi no ensino de ciências que considerei muito boa ou } \\
\text { alguma que não gostei? } \\
\text { - Quais assuntos você mais ensina do conteúdo de ciências? Como você ensina? } \\
\text { - O que me preocupa em minha sala de aula? (Situação de ensino). } \\
\text { - Como me sinto ao refletir sobre o que venho estudando? O que vem se transformando em } \\
\text { mim? (Ideias, convicções) }\end{array}$} \\
\hline $2^{a}$ Fase & $\begin{array}{l}3^{\circ} \text { encontro } \\
\text { (05 horas) }\end{array}$ & $\begin{array}{l}\text { - Conhecer e conceituar } \\
\text { WebQuest, compreendendo } \\
\text { suas características para o } \\
\text { processo de mediação na }\end{array}$ & $\begin{array}{l}\text { Apresentação, exploração e } \\
\text { discussão sobre o uso da WQ } \\
\text { em aulas de ciências, a partir } \\
\text { de }\end{array}$ \\
\hline
\end{tabular}

nossa intenção formativa de uso de plataforma simples, gratuita e de fácil utilização, a fim de que esses aspectos não se tornem empecilhos ao professor e ele centre esforços no planejamento da pesquisa orientada. 


\begin{tabular}{|c|c|c|c|}
\hline \multirow[t]{4}{*}{$\begin{array}{l}\text { Processos } \\
\text { investigativos } \\
\text { mediados pela } \\
\text { WebQuest } \\
4 \text { encontros }\end{array}$} & & $\begin{array}{llll}\begin{array}{l}\text { condição } \\
\text { aprender; }\end{array} & \text { de } & \text { ensinar } & \text { e } \\
\end{array}$ & $\begin{array}{l}\text { problematizadoras } \\
\text { diversificadas (tarefas), que } \\
\text { levem à compreensão e } \\
\text { construção de conhecimento } \\
\text { por meio de investigação } \\
\text { (Processos) e de experimentos } \\
\text { investigativos mediados pela } \\
\text { tecnologia digital (WQ), e de } \\
\text { discussão sobre o próprio } \\
\text { ensino em desenvolvimento. }\end{array}$ \\
\hline & & $\begin{array}{l}\text { - Problematizar a temática } \\
\text { Escassez Hídrica colocando } \\
\text { em evidência ensinar e prender } \\
\text { sobre o Ciclo Hidrológico. }\end{array}$ & $\begin{array}{l}\text { Desenvolvimento de atividades } \\
\text { que priorizam ações didáticas } \\
\text { de caráter investigativo, } \\
\text { permeadas por } \\
\text { problematização, as quais } \\
\text { foram divididas em cinco } \\
\text { encontros para conduzir o } \\
\text { estudo com o enfoque para os } \\
\text { fatores relacionados ao } \\
\text { problema da escassez hídrica, } \\
\text { que buscam desenvolver } \\
\text { conhecimentos para um olhar } \\
\text { crítico e avaliativo sobre a } \\
\text { situação. }\end{array}$ \\
\hline & & $\begin{array}{l}\text { - Realizar a investigação } \\
\text { formativa mediada pela } \\
\text { WebQuest com proposta de } \\
\text { Ensino de ciências destacando } \\
\text { o Ciclo Hidrológico, } \\
\text { relacionado ao Tema Escassez } \\
\text { Hídrica. }\end{array}$ & $\begin{array}{l}\text { Realizar, produzir, pesquisar, } \\
\text { investigar, registrar e socializar } \\
\text { em grupo o resultado de suas } \\
\text { tarefas realizadas. }\end{array}$ \\
\hline & & \begin{tabular}{lll} 
- Promover & \multicolumn{2}{c}{ processos na } \\
perspectiva & da & Simetria \\
Invertida e refletir & sobre o \\
realizado. & &
\end{tabular} & $\begin{array}{l}\text { Em momentos } \\
\text { durante a realização das } \\
\text { tarefas, levantar discussões } \\
\text { sobre o ensino de ciências } \\
\text { nessa perspectiva. }\end{array}$ \\
\hline $\begin{array}{l}\text { TAREFA 1/ } \\
\text { PROCESSO } 1\end{array}$ & & $\begin{array}{l}\text { A Tarefa 1: } \\
\text { - Promover diálogos e } \\
\text { apreensão das ideias iniciais } \\
\text { dos professores sobre } \\
\text { experiências em ciências, } \\
\text { sobre a importância de estudo } \\
\text { de um componente curricular } \\
\text { nos anos iniciais, } \\
\text { aproximações com recursos } \\
\text { tecnológicos e compreensão } \\
\text { do que é uma WebQuest. } \\
\text { O Processo 1: } \\
\text { - Pesquisa orientada com } \\
\text { acesso aos links sugeridos para } \\
\text { iniciar a pesquisa por meio da } \\
\text { WQ; } \\
\text { A Avaliação: } \\
\text {-Registro de suas ideias em } \\
\text { relação aos questionamentos } \\
\text { propostos na Tarefa } 1 \text {, a partir } \\
\text { das leituras indicadas nesse } \\
\text { espaço virtual. }\end{array}$ & $\begin{array}{l}\text { Após a realização da tarefa, } \\
\text { promover aos professores a } \\
\text { socialização de suas } \\
\text { aprendizagens no âmbito da } \\
\text { temática, interagindo uns com } \\
\text { os outros por meio de } \\
\text { discussão. Nesse movimento, é } \\
\text { importante provocá-los a fim } \\
\text { de que possam expor e refletir } \\
\text { sobre suas ideias. } \\
\text { Os encaminhamentos para a } \\
\text { realização da Tarefa 1/Processo } \\
1 \text { constam em detalhes na } \\
\text { WebQuest utilizada no } \\
\text { processo formativo, conforme } \\
\text { link em nota de rodapé. }\end{array}$ \\
\hline $\begin{array}{c}\text { TAREFA 2/ } \\
\text { PROCESSO } 2\end{array}$ & $4^{\circ}$ encontro & $\begin{array}{l}\text { A Tarefa } 2 \\
\text { - Elaborar respostas para uma }\end{array}$ & Os encaminhamentos para a \\
\hline
\end{tabular}




\begin{tabular}{|c|c|c|c|}
\hline $\begin{array}{l}\text { Desenvolvimento } \\
\text { de atividades } \\
\text { pautadas na } \\
\text { problematização de } \\
\text { questões sociais }\end{array}$ & (05 horas) & 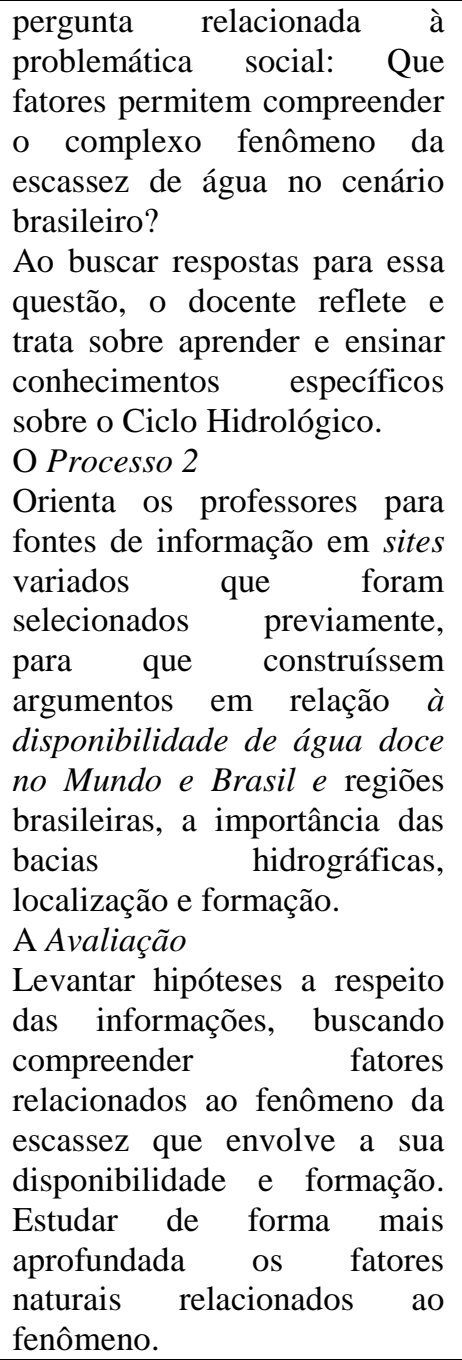 & $\begin{array}{l}\text { realização da Tarefa 2/Processo } \\
2 \text { constam em detalhes na } \\
\text { WebQuest utilizada no } \\
\text { processo formativo, conforme } \\
\text { link em nota de rodapé. } \\
\text { O encontro foi finalizado com } \\
\text { diálogos e socialização das } \\
\text { atividades realizadas pelos } \\
\text { professores e considerações } \\
\text { sobre a construção de } \\
\text { conhecimento a partir da } \\
\text { experiência vivida. }\end{array}$ \\
\hline $\begin{array}{l}\text { Proposição de } \\
\text { estudos de aspectos } \\
\text { relacionados à } \\
\text { importância do } \\
\text { Ciclo hidrológico } \\
\text { para manutenção e } \\
\text { abastecimento dos } \\
\text { reservatórios de } \\
\text { água. }\end{array}$ & $\begin{array}{l}5^{\circ} \text { encontro } \\
\text { (05 horas) }\end{array}$ & $\begin{array}{l}\text { A Tarefa } 3 \\
\text { - construção de um } \\
\text { experimento investigativo para } \\
\text { compreender processos de } \\
\text { mudanças do estado físico da } \\
\text { água, sobre o ciclo hidrológico } \\
\text { em relação a seu processo de } \\
\text { evaporação. } \\
\text { O Processo } 3 \\
\text { - orientar a construção do } \\
\text { experimento por meio do } \\
\text { acesso ao link do roteiro para } \\
\text { sua execução } \\
\text { A Avaliação } \\
\text { - indicar livros didáticos nos } \\
\text { anos iniciais que apresentam } \\
\text { esses fenômenos de forma } \\
\text { demonstrativa. }\end{array}$ & $\begin{array}{l}\text { Procedimentos: i. Apresentação } \\
\text { das situações problemas sobre } \\
\text { o tema; ii. Acompanhamento } \\
\text { de uma tentativa de explicação } \\
\text { para o problema; iii. } \\
\text { Construção do experimento; iv. } \\
\text { Discussão em grupo sobre o } \\
\text { experimento. } \\
\text { - Antes de realizar o } \\
\text { experimento, os professores } \\
\text { devem demonstrar, com } \\
\text { desenhos, suas hipóteses } \\
\text { orientadas pelo seguinte } \\
\text { questionamento: Quando } \\
\text { aquecermos a mistura o que } \\
\text { ocorrerá? Em seguida devem } \\
\text { manifestar suas visões. } \\
\text { - realizar anotações de } \\
\text { observações ocorridas no } \\
\text { experimento para reconstrução } \\
\text { do processo nas etapas } \\
\text { ocorridas (relatório final). }\end{array}$ \\
\hline $\begin{array}{c}\text { TAREFA 4/ } \\
\text { PROCESSO } 4\end{array}$ & $\begin{array}{l}6^{\circ} \text { encontro } \\
\text { (05 horas) }\end{array}$ & $\begin{array}{l}\text { A Tarefa } 4 \\
\text { - sistematizar respostas a } \\
\text { questionamentos de cunho } \\
\text { social, para ampliação do }\end{array}$ & $\begin{array}{l}\text { Os encaminhamentos para a } \\
\text { realização da Tarefa 4/Processo } \\
4 \text { constam em detalhes na }\end{array}$ \\
\hline
\end{tabular}




\begin{tabular}{|c|c|c|}
\hline $\begin{array}{l}\text { Discussão sobre o } \\
\text { uso que fazemos da } \\
\text { água, destacando } \\
\text { seu valor ético, } \\
\text { social e ambiental, } \\
\text { com intuito de gerar } \\
\text { reflexão e discussão } \\
\quad \text { sobre o seu } \\
\text { consumo e retorno } \\
\text { para o ambiente. }\end{array}$ & $\begin{array}{l}\text { estudo e resposta para questão } \\
\text { geral de investigação, seguida } \\
\text { dos seguintes questionamentos } \\
\text { propostos: 1-De onde vem a } \\
\text { água utilizada nas casas? 2- } \\
\text { Como a água chega em nossas } \\
\text { casas? 3-Quem usa a água? } 5 \text { - } \\
\text { Como a água usada retorna } \\
\text { para o ambiente? 6- A água } \\
\text { que você consome recebe } \\
\text { algum tratamento? Você sabe } \\
\text { qual seria esse tratamento? E } \\
\text { para onde vai a água depois } \\
\text { que você a utilizou? 7- Você } \\
\text { desperdiça água? Quanto vale } \\
\text { sua água? } \\
\text { O Processo } 4 \text { pesquisar os sites orientados } \\
\text { e visualizar os dois vídeos } \\
\text { disponibilizados no Youtube, } \\
\text { para obtenção, compreensão e } \\
\text { ampliação do estudo para } \\
\text { elaborar uma síntese de suas } \\
\text { investigações. } \\
\text { A Avaliação } \\
\text { - socializar no grupo seus } \\
\text { conhecimentos e reflexões } \\
\text { sobre a temática. }\end{array}$ & $\begin{array}{l}\text { WebQuest utilizada no } \\
\text { processo formativo, conforme } \\
\text { link em nota de rodapé. }\end{array}$ \\
\hline \multicolumn{3}{|c|}{$\begin{array}{l}\text { A CONCLUSÃO } \\
\text { Ao final das aprendizagens e discussões, é necessário retomar a pergunta inicial: } \\
\text { Que fatores permitem compreender o complexo fenômeno da escassez de água no cenário brasileiro? } \\
\text { Intenção: tecer reflexões de todo o processo formativo vivenciado, registrando as narrativas dos } \\
\text { significados que os professores passam a atribuir ao ensino sobre o ciclo hidrológico, alcançando a } \\
\text { dimensão social. Para tanto, laça-se a seguinte pergunta: Qual o valor de sua água? Objetiva-se } \\
\text { provocar diálogos e reflexões para além de aspectos relacionados aos conteúdos curriculares. Provocar } \\
\text { proposições relacionadas a questões sociais e ambientais. }\end{array}$} \\
\hline
\end{tabular}

Fonte: elaboração própria (2020)

A primeira fase ocorreu em 2 (dois) encontros formativos em que se caracterizou pela sondagem, sensibilização sobre a temática e movimento de reflexão docente sobre as práticas do ensino de ciências que realizam e os processos formativos que vivenciaram ao longo da vida pessoal e profissional. Essa fase foi caracterizada por diálogos em relação à temática que nos propomos a investigar, a qual levaria em consideração práticas de ensino de ciências e exigências no atual contexto educacional, em termos de novas habilidades e competências para a docência nos anos iniciais do ensino fundamental.

A segunda fase foi articulada a partir das proposições que emergiram do primeiro momento formativo, portanto, buscando atender as demandas dos professores participantes. A proposta de ensino mediada por uma WQ, vivenciada pelos professores na segunda fase, privilegiou a realização de atividades diversificadas (tarefas) pautadas na 
problematização da temática, que levassem à compreensão e construção de conhecimento por meio de investigação, de uso de tecnologia, de experimento investigativo e de discussão sobre a proposta de ensino vivenciada por eles, na condição de alunos (simetria invertida).

Quando nos referimos à realização de tarefas ${ }^{4}$, à proposta de ensino vivida pelos professores em formação, ressaltamos que não defendemos uma imposição de prática de ensino de ciências como uma receita de WebQuest a ser seguida mecanicamente, mas partimos do princípio de que as tarefas planejadas para a formação continuada possam suscitar novas proposições e possibilidades de ensino dos conteúdos científicos, com intuito de favorecer reflexão e construção de novos conhecimentos.

Assumimos as proposições de Cachapuz, Praia e Jorge (2002, p.368) quando afirmam que "é através das situações e dos problemas que se pretendem resolver é que um conceito adquire sentido para as crianças". Ou seja, "ao contextualizar e humanizar a ciência escolar se desperta o gosto pelo seu estudo". Esses autores defendem uma educação em ciência que não se preocupa somente com a aprendizagem de conteúdos específicos, mas que "garanta que tais aprendizagens se tornem úteis no dia a dia" (Cachapuz, Praia e Jorge, 2002, p. 48). Portanto, consideramos, sobremaneira, que planejar a WebQuest é planejar o ensino. Reafirmamos a WebQuest como metodologia de ensino que é favorável e potencializadora de práticas investigativas em aulas de ciências.

\section{Ensino sobre ciclo hidrológico nos anos escolares iniciais: pensar e agir a partir do vivido}

Em termos analíticos, damos a conhecer as narrativas produzidas pelos professores acerca do ensino vivenciado na proposta formativa sobre o ciclo hidrológico integrado à discussão de temática mais ampla. Pautadas no tripé formativo: Prática investigativa, experimento investigativo e tecnologia digital, colocamos no centro da discussão a necessidade de "saber aprender" para ensinar e não propriamente aspectos relacionados ao que "se deve ensinar". Sobre saber aprender, compreendemos com Freire (1996), que essa ação tem relação estreita com a curiosidade epistemológica do professor, que superando a curiosidade ingênua, se torna mais metodicamente rigoroso e permite a passagem do conhecimento do senso comum para o conhecimento científico. Logo, consideramos

\footnotetext{
${ }^{4}$ As tarefas elaboradas e constantes na WebQuest são melhor detalhadas no produto educacional disponível no seguinte endereço eletrônico: http://educapes.capes.gov.br/handle/capes/564965
} 
profícuo objetivar em processos formativos o exercício da curiosidade epistemológica em busca da produção de conhecimentos novos, e, o desenvolvimento de atitudes investigativas para a docência, é um bom começo.

Os professores de modo recorrente apresentaram manifestações sobre a relevância do uso de tecnologias digitais envolvendo o ensino do ciclo hidrológico para os anos iniciais do ensino fundamental. Passaram a compreender o potencial motivacional e de interatividade para a aprendizagem e para a realização de práticas investigativas a partir de temáticas que envolvem o cotidiano do estudante. Os docentes expressam que o uso dessa ferramenta cria possibilidades de ampliar e integrar o processo de ensino e aprendizagem, pois enriquece o estudo investigativo em questão, proporcionando a articulação entre as informações e as tarefas solicitadas, disponíveis no ambiente virtual da WQ.

A forma como Márcia, Sílvia e Luciano experienciaram o processo formativo é singular. Nos termos de Josso (2010), experienciar é ter uma presença consciente e reflexiva nas ações formadoras das quais participa. É indagar-se de forma consciente sobre a experiência de formação pelo qual passou, refletir sobre ela e pensar sobre o que fará adiante com as aprendizagens conquistadas. Nesse movimento de ação-reflexão-ação/nova compreensão, há a copresença do passado, presente e futuro na formação do professor (Fraiha-Martins, 2014).

Nesse processo, eles manifestam vários entendimentos sobre o uso da WQ. Ademais, refletem sobre práticas passadas, estabelecendo relações entre o antes e o depois para relatar sobre o entendimento do uso das tecnologias digitais em aula. A respeito das orientações e sistematizações de pesquisa online na WQ, Márcia destaca: $O$ uso da WQ chamou minha atenção para saber orientar melhor as pesquisas. Quando você desenvolveu o caminhozinho claro e sistemático, eu vi que é melhor para a aprendizagem do aluno, porque foi melhor para mim. A professora Márcia reconhece a importância da orientação e planejamento para realização de uma atividade que envolva pesquisa na Web, a partir de um objetivo claro a ser pesquisado, principalmente para crianças do $4^{\circ}$ e $5^{\circ}$ ano do fundamental. Tal experiência vivenciada na formação a fez pensar e refletir sobre suas práticas anteriores, ressaltando: quando eu peço para os alunos fazerem pesquisa na internet, eu não sistematizo essa ação.

Ao estabelecer uma relação com suas ações passadas, Marcia mais do que perceber a importância da pesquisa orientada, toma consciência de que a maneira como realizava 
esse tipo de atividade, ampliando o assunto sem direcionar essa busca, era consequência da falta de objetivos claros e de sua pouca experiência com uso de internet em aula. Assim, ao vivenciar o uso na condição de aluna, Marcia expressa: penso o quanto meu aluno deveria ficar perdido quando ia pesquisar algo na internet com um mundo de informações. Neste percurso, ela passa a compreender a partir do vivido na formação, que para realizar tal atividade é necessário planejar e sistematizar a orientação para o desenvolvimento de pesquisas com uso da Web.

Sobre as tecnologias digitais, Moran (2007, p.90) aponta:

Os educadores costumam começar utilizando-as para melhorar o desempenho dentro dos padrões existentes. Mais tarde, animam-se a realizar algumas mudanças pontuais e, só depois de alguns anos, é que educadores e instituições são capazes de propor inovações, mudanças mais profundas em relação ao que vinham fazendo até então. Não basta ter acesso à tecnologia para ter o domínio pedagógico. Há um tempo grande entre conhecer, utilizar e modificar o processo.

Esse percurso de amadurecimento profissional para a docência com uso dessas tecnologias, a nosso ver, é possível se efetivar, na medida em que o professor se envolver em processos de (auto) formação que invistam no estudo das próprias práticas cotidianas, pois assim ele se permitirá conhecer, refletir sobre o objeto conhecido, utilizar, refletir sobre a prática ocorrida e projetar novas práticas, agora mais refinadas. Consideramos que o design de formação investigado potencializou retroalimentação para a própria docência nos anos escolares iniciais.

Em relação à professora Silvia, quando se manifesta a respeito do uso da ferramenta digital no processo de ensino vivenciado na formação continuada em questão, situou seu entendimento do uso dessa ferramenta para reforçar conteúdos já estudados, posicionandose mais como 'consumidora' do que 'produtora' de informação e/ou conhecimento, conforme expressa: Além de fazer uso de livros, gosto de trabalhar o ciclo hidrológico passando alguns vídeos para complementar e facilitar a compreensão do assunto, para não ficar cansativo. Concordando com Silvia, o professor Luciano faz o seguinte apontamento, nos primeiros momentos formativos, a respeito do uso da ferramenta digital WQ: Considerei muito bom o encaminhamento proposto nas atividades. Gosto muito de usar celular e vídeo nas aulas de ciências e história, pois acho que é mais fácil para o desenvolvimento e complementação do trabalho em sala. O professor reconhece a importância do uso desses recursos tecnológicos para o desenvolvimento de sua prática, mas parece revelar uma compreensão ainda limitada. 
Luciano pontua: para que os estudantes comparem a imagem no livro com outro tipo de imagem, uso meu celular mostrando como pesquisar e, em seguida, peço para eles copiarem. Essa é a única coisa que uso de tecnologia. É possível inferir, que embora o professor reconheça a importância do uso desses recursos em suas práticas no ensino de ciências, a base é o livro para o corte, a colagem e as cópias. Esses recursos podem ser usados como meio para ensinar ciências, mas consideramos que é preciso que o professor promova processos de interação, diálogos e discussão em sala.

Nessa perspectiva, Silvia e Luciano evidenciaram que faziam uso de tecnologias digitais somente como fonte de informações. Coll, Mouri e Onrubia (2010), em suas pesquisas, revelam que nas escolas e salas de aula se faz uso das tecnologias digitais somente com intuito de obtenção de fonte de informação. Para os autores essa perspectiva de uso se torna limitada não proporcionando mudanças nas práticas de ensino dos professores. Segundo a visão desses autores, pensar no uso das tecnologias somente como obtenção de fonte de informação faz com que os professores e alunos assumam uma postura mais de consulta à informação do que de "produtor" de conhecimento.

Compreendemos que a WebQuest, como metodologia de ensino de ciências, que visa a pesquisa orientada para alunos dos anos escolares iniciais, é capaz de cria condições para que o professor possa organizar sua prática de ensino integrando outras metodologias com vistas à autoria discente, tais como uso de experimentos investigativos, outro elemento do tripé formativo definido por nós. Segundo Zancul (2008, p.68) ao tratar do experimento como uma ferramenta de construção do conhecimento, destaca que a "busca de informações e de procura de respostas para perguntas que as crianças são estimuladas a formular dentro e fora da escola, permite o ensino voltado para a formação de um cidadão crítico e participativo". Nessa perspectiva, o experimento assume outros propósitos. Giordan $(1999$, p.44) corrobora com essa perspectiva de uso de experimentos em aula, ao dizer que:

Tomar a experimentação como parte de um processo pleno de investigação é uma necessidade, reconhecida entre aqueles que pensam e fazem o ensino de ciências, pois a formação do pensamento e das atitudes do sujeito deve se dar preferencialmente nos entremeios de atividades investigativas.

Portanto, o uso do experimento como parte de processo investigativo torna-se terreno extremamente fértil para a construção do conhecimento científico e para o uso 
social desse conhecimento, ao fazer sentido para a vida cotidiana do aprendiz ${ }^{5}$. Sendo assim, a WQ proporciona ao professor um exercício diferente de planejar e orientar a pesquisa escolar. Dessa forma, permitirá o acesso às tecnologias que já fazem parte do cotidiano da infância, bem como potencializará o trabalho colaborativo por meio de práticas investigativas.

A respeito da prática investigativa, como elemento fundamental do tripé formativo, ao mesmo tempo em que o professor/aluno busca compreender uma determinada problemática relacionada ao cotidiano, ele constrói e aprofunda conhecimentos específicos que explicam um fenômeno que está articulado à discussão. Trabalhar o ensino de ciências, a partir de uma temática que crie possibilidades de integração com outras áreas do conhecimento, é propiciar a obtenção de conteúdos procedimentais e atitudinais, onde esses sujeitos (professor/aluno) poderão ser autônomos no sentido de refletirem sobre suas aprendizagens e, assim poderão construir novos conhecimentos.

Ficou evidente no processo analítico que a maioria dos docentes envolvidos utilizam o livro didático como principal fonte para o ensino de ciências em sala de aula, em especial, para o ensino do ciclo hidrológico. Luciano diz: Minha própria base é o livro, não consigo trabalhar esse conteúdo de maneira aprofundada. Já a professora Silvia relata: trabalho o conteúdo do Ciclo Hidrológico de forma bem simples, vejo que a questão do ciclo é bastante abordada nos livros didáticos, por isso faço uso desse material didático

Os professores Luciano e Sílvia, ao narrarem como trabalham esse tema, pontuam que fazem o uso recorrente do livro didático em suas práticas. Segundo Longhini (2008), a falta de conhecimento do conteúdo específico para ensinar ciências faz com que os professores utilizem frequentemente o livro didático em suas práticas para "driblar" suas inseguranças e carências oriundas desde a formação inicial, pois muitos são professores "polivalentes". No dizer de Longhini (2008, p. 248), "o que afeta diretamente o desenvolvimento dos conteúdos científicos em sala de aula, é a maneira como o docente é formado ou até mesmo a visão que possui sobre o que é Ciência e a atividade científica".

A professora Marcia ao discorrer sobre a maneira como sistematiza o estudo desse tema em sala, diz: Inicio o estudo do ciclo da água com uma roda de conversa para debater as ideias iniciais dos alunos, depois uso o livro didático para estudo do assunto, faço uso do celular para que comparem imagens com as do livro e passo um questionário

\footnotetext{
${ }^{5}$ Embora o experimento investigativo pertença ao design de formação em foco, privilegiamos a discussão sobre as repercussões desse elemento formativo em outra publicação.
} 
sobre o tema. Embora ela faça uso de vários recursos buscando dinamizar o estudo e inicie fazendo o levantamento dos conhecimentos prévios dos alunos, ela faz do livro didático o seu principal recurso para o estudo do assunto. Assim como Marcia, os docentes indicam durante a formação estar ancorados na concepção de ensino pautada na transmissão de informação. Evidenciam ao remeterem-se ao passado que não problematizam os conteúdos a serem abordados, indicando que o uso do vídeo e celular não é para discutir/problematizar, colocando o assunto em um contexto social, e sim para ilustrar.

Partindo dessa realidade, ao desenvolvermos as análises relacionando-as aos sentidos que os professores atribuem às práticas investigativas desenvolvidas durante o design de formação continuada, evidenciamos indícios de novos pensamentos e atitudes docentes a respeito do ensino sobre o ciclo hidrológico em sala de aula. A professora Marcia ao discorrer sobre o uso dessa proposta metodológica para o ensino de ciências a partir da experiência formativa, apontou que: houve um encaminhamento de perguntas, análise e consultas que posso utilizar com outros recursos para ensinar o ciclo hidrológico, como mapa, gráfico, tabelas. O aluno vai gostar de aprender dessa forma, onde ele pesquisa, investiga, constrói, produz e vivencia. No mesmo caminho, Luciano destaca: Para mim, a prática investigativa realizada na formação foi muito interessante. Considerei mais eficiente, vai dar mais qualidade ao ensino de ciências $e$, consequentemente, ao processo de aprendizagem do aluno.

Para Carvalho (2009) a elaboração de estratégias de resolução e realização de experiências, por meio da investigação, provoca a participação dos estudantes, conduzindo à atitude questionadora, observação e à compreensão de determinado fenômeno em relação a sua própria realidade durante o processo investigativo em aula. Segundo Carvalho et al (2009, p.13), "quando levamos nossos alunos a refletir sobre os problemas experimentais que são capazes de resolver, ensino-lhes, mais do que conceitos pontuais, a pensar cientificamente o mundo, a construir uma visão de mundo".

Na direção de propiciar práticas que favoreçam a compreensão da realidade social, os professores Luciano e Márcia levantaram outro aspecto importante em relação ao estudo com prática investigativa ao partir de uma problemática social, no caso, a escassez hídrica. Luciano expressa: Em relação à questão do uso social do conhecimento sobre a temática que estudamos, é fundamental trabalhar em sala de aula não somente as mudanças de estados da água, mas questões relacionadas à conservação e manutenção desse recurso. $\mathrm{O}$ professor apresenta indícios de compreensão do potencial de abrangência social, quando 
temáticas que são noticiadas pelos meios de comunicação são lançadas aos alunos na forma metodológica de WebQuest. Márcia também revela: as tarefas nos levam não somente a perceber as questões do cuidado com a água, mas também a questão de como está distribuído esse recurso em algumas regiões, porque em algumas a quantidade é pouca, em outras não. É preciso observar a questão da distribuição, da formação e da disponibilidade hídrica.

Portanto, os professores despertam para a relevância metodológica que investe em problemáticas do cotidiano do aluno, indicando que o ensino necessita integrar-se à realidade e necessidade dos estudantes. Nesse caminho "O ensino deve potencializar a aprendizagem. Ensino e aprendizagem precisam ser entendidos como uma unidade, dois lados de uma mesma moeda, duas faces de uma mesma aula" (CARVALHO et al, 2009, p. $10)$.

Em outro momento, após a formação, os professores compartilharam um planejamento integrado para o $5^{\circ}$ ano sobre a temática, onde buscaram no livro didático como de costume para pensar na sistematização da prática. Luciano revela:

Agora depois da formação continuada que vivenciamos com você passamos a olhar de forma mais aprofundada para o tema recursos hídricos no $5^{\circ}$ ano. A maioria dos livros não trabalha com essa problematização que experienciamos na formação com você, achamos uma proposta boa que toca no cotidiano, mas não com essa problematização que foi realizada na formação.

Embora o professor Luciano tenha evidenciado que retoma o livro didático, ele mostra que passa a pensar de modo diferenciado sobre o que está proposto no livro. Passa a avaliar de forma mais crítica, estabelecendo relação com o que vivenciou na formação continuada. Sendo assim, os professores sinalizaram que as práticas de investigação em aula, planejadas na WebQuest, potencializam o processo de estudo favorecendo o questionamento, o diálogo, a construção de argumentos e a comunicação dos resultados do estudo. Ou seja, as perguntas acabam provocando nos docentes e discentes atitudes investigativas, desencadeando processos de reflexão e de construção de conhecimento.

\section{Considerações finais}

Os resultados revelam que as práticas dos professores têm relação direta com as experiências de formação pelas quais passaram, bem como indicam a pouca compreensão na preparação de planejamentos relacionados à iniciação científica por meio da disciplina ciências. Os docentes manifestam que os planos escolares de formação continuada de 
professores na rede onde atuam não priorizam o ensino de ciências e, quando ocorrem, pouco repercutem positivamente na prática docente sobre ensinar ciências para as crianças.

Compreendemos que modelos de formação continuada formatados para ocorrer em larga escala pouco alcançam, de fato, a cultura interna escolar em termos de docência. Para pensar no desenvolvimento de formação continuada na educação básica é necessário ter compreensão dos contextos e da estrutura escolar. É considerar como ponto de partida as narrativas dos professores sobre suas práticas profissionais, olhando o passado com a visão do presente, em busca de projetar o futuro didático. Não é possível desconsiderar o protagonismo docente durante as práticas formadoras, tampouco incentivar a reprodução de práticas antigas com nova roupagem.

Essa especial escuta é capaz de permitir a tomada de consciência dos professores de que são sujeitos ativos das ações propostas. É preciso conhecer seus anseios. Ao sermos capazes de mobilizar perspectivas de mudança, nos respectivos contextos docentes, nos permite romper com o caráter instrumentalista da formação, que impõe um passo a passo de uma determinada abordagem metodológica. É necessário potencializar o desenvolvimento humano e social, em que um coletivo em reflexão na e sobre a ação, pode contribuir para superação de obstáculos na ação docente.

Portanto, o design de formação continuada aqui proposto buscou assumir como princípio a formação do professor pesquisador sobre a própria prática, pautado no tripé formativo, prática investigativa - experimento investigativo - tecnologia digital, assumindo como pano de fundo a perspectiva metodológica da simetria invertida e o contexto da própria escola e seus personagens. Assim entendemos ser um modo de pôr no centro da formação a realidade vivida pelo professor e suas necessidades.

O modelo formativo proposto nesta pesquisa vai ao encontro de um processo em que o professor, imerso no seu contexto escolar, possa refletir sobre sua prática para repensá-la. Sendo assim, destacamos a seguir algumas proposições que expressam o momento formativo e seus desdobramentos na formação, objetivando contribuir com outros processos de formação continuada de professores, e também com professores ou formadores de professores que se identifiquem com a perspectiva metodológica desenvolvida. São elas:

$\checkmark$ Os professores estabelecem relações com outras propostas vividas ao longo de sua profissão, projetando, assim, outros movimentos de formação continuada que 
gostariam de ter. Reconhecem a relevância de práticas que discutam sobre a problematização dos conteúdos a serem ensinados de maneira a alcançar o nível social do conhecimento escolar;

$\checkmark$ Os professores consideram ser mais profícuo a forma de experienciar a formação continuada, refletindo sobre suas próprias práticas para pensar o ensino por meio de questões deflagradoras como: Por que ensino do jeito que ensino? Por que ensinar de um jeito e não de outro?

$\checkmark$ Os professores ressaltaram que o uso de WebQuest em aula cria possibilidades de ampliar e integrar o processo de ensino e aprendizagem, pois enriquece o estudo investigativo em questão, proporcionando interdisciplinaridade e articulação com as várias tarefas planejadas e conduzidas pela pesquisa orientada elaborada na WQ;

$\checkmark$ Propostas de formação que privilegiam o uso de tecnologias digitais encorajam e contribuem, de um modo ou de outro, para a incorporação desses recursos às práticas de ensino do professor, e permitem que, paulatinamente, o docente avance da prática de uso limitada para a prática de uso potencial das tecnologias digitais em situações de ensino;

$\checkmark$ A prática investigativa em aula foi destacada como excelente possibilidade de aprender ciências, pois ao mesmo tempo em que o professor/aluno busca compreender uma determinada problemática relacionada a um tema, constrói e aprofunda conhecimentos específicos que melhor explicam um fenômeno que está articulado na discussão.

$\checkmark$ Práticas formadoras dessa natureza podem tornar possível o rompimento com o ensino fragmentado e conteudista, ainda marcante nas práticas docentes, embora os documentos oficiais para o ensino de ciências nos anos escolares iniciais sinalizem práticas que assumam o contexto do aluno, em busca da construção de conhecimentos do aprendiz para a vida.

Por fim, consideramos que, quanto mais o professor viver experiências de formação que priorizem o conteúdo e seus aprofundamentos e combinem as múltiplas formas de ensinar esse conteúdo, quanto mais ele será capaz de fazer as melhores escolhas pedagógicas para aquela determinada turma dos anos escolares iniciais com a qual interage. Em igual relevância, compreendemos que quanto maior for a diversidade metodológica utilizada para ensinar determinado conteúdo, maior será o alcance das aprendizagens em um determinado grupo de estudantes, pois cada um tem seu ritmo e sua 
melhor maneira de aprender, seja por meio da audição, da manipulação ou da visualização, ou ainda, por outras formas de combinação. As tecnologias digitais podem ser uma boa aliada para a criatividade do professor.

\section{Referências}

Abar, C. A. A., e Barbosa, L. M. (2008). Webquest: um desafio para o professor! São Paulo: Avercamp.

Brasil. (1997). Parâmetros curriculares nacionais: ciências naturais. Secretaria de Educação Fundamental. Brasília: http://portal.mec.gov.br/seb/arquivos/pdf/livro04.pdf.

Brasil. (2012). Elementos conceituais e metodológicos para definição dos direitos de aprendizagem e desenvolvimento do Ciclo de Alfabetização $\left(1^{\circ}, 2^{o}\right.$ e $3^{o}$ anos $)$ do Ensino Fundamental. Ministério da Educação. Secretaria da Educação Básica. Brasília:

MEC/SEB. http://portal.mec.gov.br/index.php?option=com_docman\&view=download\&alias $=1$ 2827-texto-referencia-consulta-publica-2013-cne-pdf\&category_slug=marco-2013pdf\&Itemid=30192.

Brasil. (2017). Base Nacional Comum Curricular (BNCC). Educação é a Base. Brasília, MEC/CONSED/UNDIME. http://basenacionalcomum.mec.gov.br/images/BNCC_EI_EF_110518_versaofinal site.pdf.

Cachapuz, A. et al (orgs.). (2011). A Necessária Renovação no Ensino de Ciências. 3 ed. Cortez.

Cachapuz, A. F.; Praia, J., \& Jorge, M. (2002). Ciência, Educação em Ciência e Ensino de Ciências (Temas de Investigação, 26), Ministério da Educação, Lisboa.

Carvalho, A. M. P. et al. (2009). Ciências no Ensino Fundamental: o conhecimento físico. São Paulo: Editora Scipione. (Coleção Pensamento e Ação na Sala de Aula)

Castro E. B. (2018). Formação de Professores em Contexto: processo de investigação-ação sobre a abordagem de conhecimento químico nos anos iniciais. Dissertação de Mestrado em Docência em Educação em Ciências e Matemática. Universidade Federal do Pará. http://repositorio.ufpa.br:8080/jspui/handle/2011/12434.

Chassot, A. (2006). Alfabetização científica: questões e desafios para a educação. $4^{\mathrm{a}}$ Ed. Ed. Unijuí. (Coleção educação em química).

Clandinin, D. J, \& Connelly, F. M. (2011). Pesquisa Narrativa: experiências e história na pesquisa qualitativa. Tradução: Grupo de Pesquisa Narrativa e Educação de Professores ILEEL/UFU. EDUFU.

Coll, C; Mauri, T., \& Onrubia, J. (2010). As tecnologias da informação e comunicação na educação: do projeto técnico-pedagógico às práticas de uso. In: Coll, C., \& Monereo, C. Psicologia da educação virtual: aprender e ensinar com as tecnologias da informação e da comunicação. Artmed.

Cunha, M. I. (1997). Conta-me Agora! As narrativas como alternativas pedagógicas na pesquisa e no ensino. Educação e Realidade, Porto Alegre, v.18, n.2, p.21-35. 
Delors, J. (org.). (1998). Educação: um tesouro a descobrir. Relatório para a UNESCO da Comissão Internacional sobre Educação para o século XXI. UNESCO: Publicação MEC,

1998. http://www.pucsp.br/ecopolitica/documentos/cultura_da_paz/docs/Dellors_alli_Rel atorio_Unesco_Educacao_tesouro_descobrir_2008.pdf.

Deslauriers, J., \& Kérisit, M. (2008). O delineamento de pesquisa qualitativa. In: Poupart, $\mathrm{J}$. et al. A pesquisa qualitativa: enfoques epistemológicos e metodológicos (pp. 127-153). Trad. Ana Cristina Nasser. Vozes.

Dodge, B. (1995). A Techinique for Internet - Based Learning. Trad. Por Jarbas Novelino Barato. The Distance http:www.webquest.futuro.usp.br/artigos/textos_bernie.html

Fraiha-Martins, F. (2014). Significação do ensino de Ciências e Matemática em processos de letramento científico-digital. Tese de Doutorado em Educação em Ciências e Matemáticas. Universidade Federal do Pará. http://repositorio.ufpa.br/jspui/handle/2011/8505.

Freire, P. (1996). Pedagogia da Autonomia: Saberes necessários à prática educativa. 33 ed. Paz e Terra. (Coleção Leitura)

Galiazzi, M. C. (2003). Educar pela pesquisa: Ambiente de formação de professores de Ciências. Ed. Unijuí.

Giordan, M. (1999). O papel da experimentação no ensino de ciências. Química nova na escola, 10(10), 43-49. http://qnesc.sbq.org.br/online/qnesc10/pesquisa.pdf

Imbernón, F. (2006). Formação docente e profissional: formar-se para a mudança e a incerteza. Trad. Silvana Cobucci Leite. 4. Ed. Cortez.

Josso, M. C. (2004). Experiências de vida e formação. Cortez.

Longhini, M. D. (2008). O conhecimento do conteúdo científico e a formação do professor das séries iniciais do ensino fundamental. Investigações em Ensino de Ciências, 13(2), 241-253. https://www.if.ufrgs.br/cref/ojs/index.php/ienci/article/view/441.

Lorenzetti, L., \& Delizoicov, D. (2001). Alfabetização científica no contexto das séries iniciais. Ensaio - Pesquisa em Educação em Ciências, v. 3, n. 1. P.45-61. Jan-Jun.

Minayo, M. C. de S. (2008). O desafio do conhecimento: pesquisa qualitativa em saúde. Hucitec.

Moraes, R., \& Galiazzi, M. C. (2007). Análise textual discursiva. Unijuí.

Moran, J. M. (2007). A Educação que desejamos: novos desafios e como chegar lá. Papirus.

Moreira A. S. (2019). Interações Ecológicas por meio da Literatura Infantil: Formação continuada assistida em parceria na perspectiva do letramento. Dissertação de Mestrado em Docência em Educação em Ciências e Matemática. Universidade Federal do

Pará. https://drive.google.com/file/d/1p9h4JTZAcPs0QxtwXgMV3m061ZICwXJu/view.

Prado, M. E. B. B. (2006). A mediação pedagógica: suas relações e interdependências. XVII Simpósio Brasileiro de Informática na Educação (SBIE). Brasília, DF. 
Raboni, P. C. A. (2002). Atividades práticas de ciências naturais na formação de professores para as séries iniciais. Tese de Doutorado. Universidade Estadual de Campinas. http://repositorio.unicamp.br/jspui/handle/REPOSIP/251270.

Sales S. M, T. (2019). Contribuições de processos formativos a alunos de Anos iniciais: práticas interdisciplinares. 2019. Dissertação de Mestrado em Docência em Educação em Ciências e Matemática. Universidade Federal do Pará.

Shulman, L. S. (1986). Those who understand: knowledge growth in teaching. Educational Researcher, 15(2), p. 4-14.

Soares, G. F. A. (2017). Ensino de ciências por investigação: um desafio à formação dos professores dos anos escolares iniciais. Dissertação de Mestrado em Docência em Educação em Ciências e Matemática. Universidade Federal do Pará. http://repositorio.ufpa.br/jspui/handle/2011/10523.

Autores:

Ana Elisabeth Dias Pereira Cavalcante

Mestranda do Programa de Pós-Graduação em Docência em Educação em Ciências e Matemáticas (PPGDOC) da Universidade Federal do Pará (UFPA/Brasil). Graduação em Licenciatura Integrada em Ciências, Matemática e Linguagens pela Universidade Federal do Pará (2016). Membro do grupo de pesquisa de formação de professores (Trans)Formação, vinculado ao IEMCI/UFPA. E-mail: bethdcp@ hotmail.com

France Fraiha-Martins

Doutorado em Educação em Ciências e Matemática pela Universidade Federal do Pará (2014). Mestrado em Educação em Ciências e Matemática pela Universidade Federal do Pará (2009). Especialização em Informática na Educação pelo Centro Universitário do Pará (2001). Graduação em Tecnologia em Processamento de Dados pelo Centro Universitário do Pará (1995). É docente da Universidade Federal do Pará, lotada no Instituto de Educação Matemática e Científica. É membro do grupo de pesquisa de formação de professores (TRANS) FORMAÇÃO, registrado no CNPq. Desenvolve pesquisa narrativa na linha Formação de Professores com trabalhos voltados para a Educação a Distância e para o uso de Tecnologias Digitais em situações de ensino. E-mail: francefraiha@ufpa.br 